\title{
Impact of SARS-CoV-2 Pandemic on Kidney Cancer Management
}

\author{
Melissa Bersanelli ${ }^{\mathrm{a}}$ and Camillo Porta ${ }^{\mathrm{b}, *}$ \\ ${ }^{a}$ Medicine and Surgery Department, University of Parma and Medical Oncology Unit, \\ University Hospital of Parma, Parma, Italy \\ ${ }^{\mathrm{b}}$ Department of Biomedical Sciences and Human Oncology, University of Bari 'A. Moro' \\ and Division of Medical Oncology, A.O.U. Consorziale Policlinico di Bari, Bari, Italy
}

Received 27 January 2021

Accepted 8 March 2021

Pre-press 30 March 2021

Published 16 June 2021

\begin{abstract}
.
BACKGROUND: The SARS-CoV-2 pandemic still has a huge impact on the management of many chronic diseases such as cancer. Few data are presently available reagarding how the management of renal cell carcinoma (RCC) has changed due to this unprecedented situation.

OBJECTIVE: To discuss the challenges and issues of the diagnosis and treatment of RCC in the COVID-19 era, and to provide recommendations based on the collected literature and our personal experience.

METHODS: Systematic review of the available Literature regarding the management of RCC during the SARS-CoV-2 pandemic.

RESULTS: Our review showed a prevalence of narrative publications, raising the issue of the real relevance of the evidence retrieved. Indeed, the only original data about RCC and COVID-19 found were a small retrospective case series and two surveys, providing either patients' or physicians' viewpoints.

CONCLUSIONS: The expected delayed diagnosis of RCC could lead to an increase of advanced/metastatic cases; thus, proper therapeutic choices for patients with small renal masses should be carefully evaluated case by case, in order to avoid negative effects on long-term survival rates. The controversial interaction between immune checkpoint blockade and COVID-19 pathogenesis is more hypothetical than evidence-based, and thus immunotherapy should not be denied, whenever appropriate. To avoid treatments which won't have an impact on patients' survival, a honest and accurate evaluation of the cost/benefit ratio of each treatment option should be always performed. Finally, SARS-CoV-2 swab positivity should not prevent the continuation of ongoing active treatments in asymptomatic cases, or or after symptoms' resolution.
\end{abstract}

Keywords: SARS-CoV-2 pandemic, COVID-19, renal cell carcinoma, diagnosis, treatment

\section{INTRODUCTION}

While the "COVID-19 era", unfortunately far from being relegated to 2019 , is currently still ongoing,

\footnotetext{
*Correspondence to: Prof. Camillo Porta, Chair of Oncology, Department of Biomedical Sciences and Human Oncology, University of Bari 'A. Moro', A.O.U. Consorziale Policlinico di Bari, Piazza Giulio Cesare 11, 70124 Bari, Italy. Tel.: +39 080 5594167; Fax: +39 080 5593477; E-mail: camillo.porta@gmail.com.
}

every branch of Medicine is facing an unavoidable rebalancing of the risk-benefit ratio. Every procedure, every single clinical choice, is being reweighed considering the health system's new asset, currently heavily burdened by the pandemic. From the delay of the necessary diagnostic procedures, to the replanning and amendment of clinical trials, the entire health service chain has been shaken and redesigned in light of the emergency due to SARS-CoV-2 
diffusion $[1,2]$. As medical oncologists, we have the ethical mission of pursuing our cancer patients' interest, balancing, on one hand, their right to the best diagnostic-therapeutic process, and on the other hand, their risk of contracting COVID-19 while following our therapeutic indications [3]. Conversly, diagnostic procedures and anticancer treatments presently constitute both the only opportunity of improving our patients' outcome, as well as risk factors for COVID-related severe events. Cancer patients are highly exposed to high-risk hospital contacts (among patients themselves and with the healthcare personnel), thus increasing the probability of being infected. Moreover, they are exposed to immunosuppression, iatrogenic consequences, and adverse events generated by anticancer therapies, often leading to a significant risk of complications in case of SARSCoV-2 infection [4-7]. With this scale to keep in difficult balance, and facing the concrete unavailability of the usually high-level medical services of developed countries (since most of our healthcare resources are currently strongly dedicated to the management of COVID-19 outbreaks), we should rethink priorities and redesign flow-charts for our current approach to genitourinary malignancies [8]. The multidisciplinary discussion has never been more critical than now for an optimized and tailored management of cancer patients, basing on the peculiar local realities and a general pandemic-based common-sense.

Since the beginning of the first COVID-19 outbreak, the sharing of all the available knowledge has been important for supporting evidence-based decisions. With the same aim, we planned the present review to provide balanced coverage of this timely issue, and its controversial aspects, reporting all the evidence about the diagnostic and therapeutic approach to genitourinary cancers, particularly renal cell carcinoma (RCC), in the COVID-19 era. Moreover, we tried to address some crucial controversies in this field, discussing the challenges of diagnosing and treating renal tumors in these dark times, and offering our recommendations based on the collected literature and our personal experience during the pandemic.

\section{METHODS}

The present review was performed in compliance with PRISMA guidelines [9]. We searched PubMed for studies published in English language from the inception of the database to November 18,
2020. The two investigators (MB and CP) independently performed the search. The following terms were used: $(((($ genitourinary cancers[All Fields]) OR (renal cancer[MeSH Terms])) OR (urothelial cancer[MeSH Terms])) OR (prostate cancer[MeSH Terms])) OR (testicular cancer[MeSH Terms])) AND (COVID-19[MeSH Terms]). After the first selection of publications, we screened the included articles' references for the recovery of any further eligible publication. Inclusion criteria were: 1) full-text publications concerning the issue of genitourinary cancer management during COVID-19 pandemic, from diagnosis to local or systemic treatments; 2) any type of narrative, systematic or investigational paper, including original investigations, case series/ reports, reviews, meta-analyses, commentaries, consensus, editorials, and letters; 3) full-text in English. We excluded non-pertinent publications and works published as abstract only. The two investigators independently reviewed publications to select the eligible articles, while a single reviewer (MB) categorized the papers based on different primary tumors and then classified the retrieved publications based on article type for each primary genitourinary cancer. A focus on kidney cancer publications was preplanned: the two investigators extracted, reported, and commented on data from all the publications concerning this disease. Due to the expected high heterogeneity of the studies, we planned a qualitative analysis only. After considering the published data, we have drawn up some consensus recommendations about key issues of interest in managing kidney tumors during the COVID-19 pandemic.

\section{RESULTS}

\section{General results}

Our search retrieved 361 potentially relevant publications: 274 were excluded as not pertinent, while 87 works were identified for more detailed evaluation and inclusion in the present review. All published in 2020, these papers were screened and classified according to the primary genitourinary tumor and, within each primary cancer category, basing on the article type. Figure 1 describes the search flow and the selection and classification of the eligible publications [10-99]. The heterogeneity of the studies was extremely high. The issue discussed included diagnostics, surgery, radiotherapy, and systemic treatments in the COVID-19 era. Overall, narrative papers were 60 out of 87 works, without original data, only 


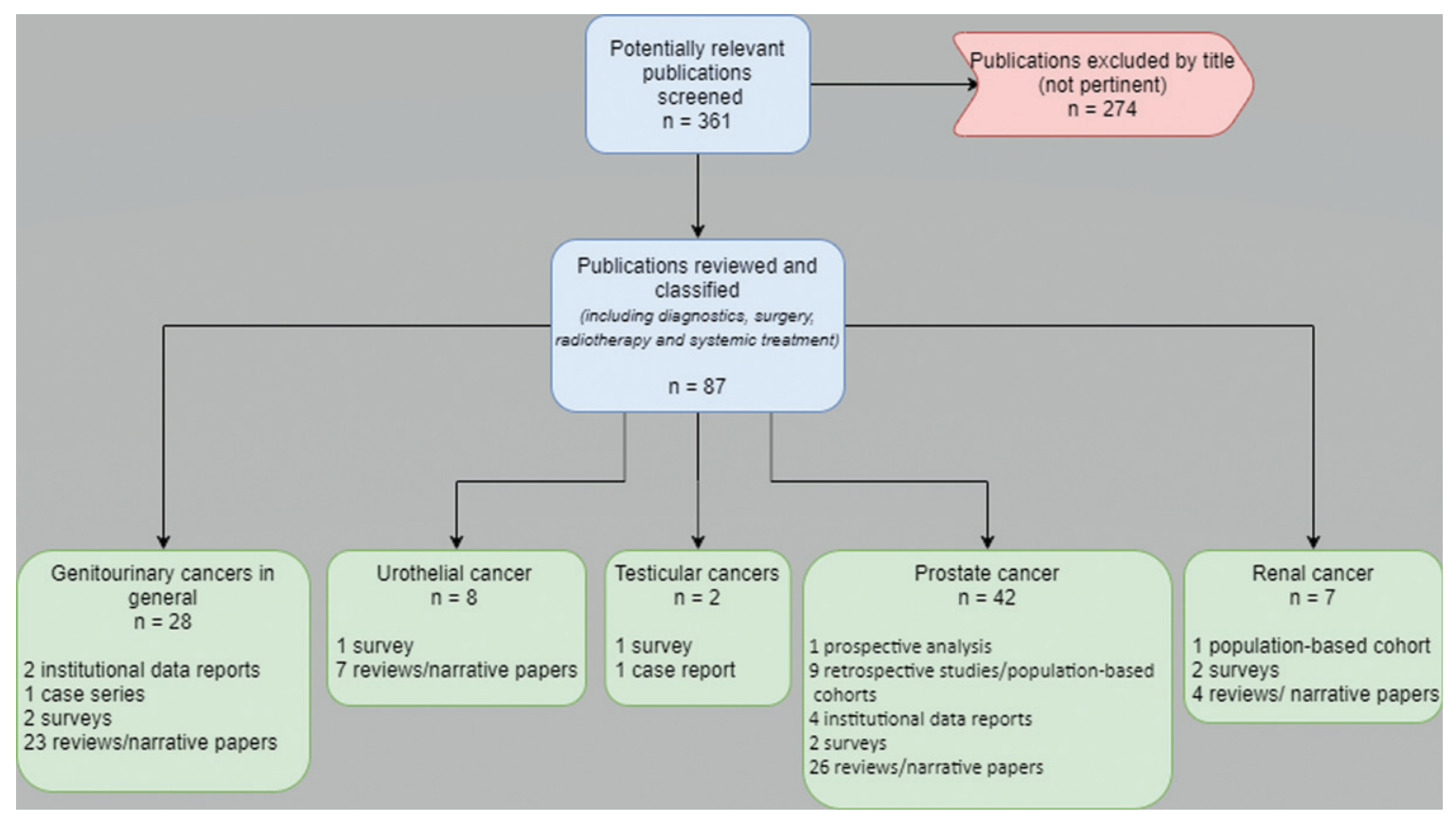

Fig. 1. Flow diagram of the study selection process for the qualitative analysis.

reporting or discussing results from other original investigations. The only prospective evidence came from a prostate cancer patient cohort, examining the role of androgen deprivation therapy (ADT) concerning SARS-CoV-2 infection and concluding that ADT did not appear to be protective against COVID-19 [79]. Retrospective studies and institutional patient cohorts were reported in 16 publications throughout all genitourinary malignancies. At least one survey was conducted for each tumor type, with eight surveys published overall [37, 41, 48, 93-95, 98, 99]. Finally, few case reports completed the roster of the selected publications (Fig. 1).

The patient population of the original reports ranged from one to 4532 cases [47, 64]. The primary tumor was mostly prostate cancer [49-91]. Seven works were retrieved on RCC: only one was an original investigation, represented by a retrospective population-based cohort [92]; two were surveys (one of which with duplicated publication) [93-95], and four were narrative papers [96-99].

\section{Evidence on RCC}

The only original study, conducted in the Russian Federation, retrospectively reported a total of 17 SARS-CoV-2-positive RCC patients, with pneumonia developing in $53 \%$ of cases. Of them, $8(42 \%)$ were affected by metastatic disease, and 7 were undergoing active treatment. With the limitation of small numbers, the authors described a relatively low lethality of COVID-19, with 2 patients only (11.8\%) who died after the infection. The median delay of RCC treatment (surgery or systemic) was 27.6 days, but renal disease progression was found only in one patient during COVID-19 or within the next 30 days. Hospitalization was required in the majority of patients (10/17) [92].

One of the surveys, by Aeppli et al., was conducted interviewing RCC experts to ascertain their systemic treatment algorithm outside and during the coronavirus pandemic [93]. The authors observed that attitudes towards metastatic RCC treatment modifications diverge based on resource constraints in different countries. The most common modifications during the pandemic were avoidance of immune checkpoint inhibitors (ICIs), and frequent preference for tyrosine kinase inhibitor (TKI) monotherapy. Most oncologists changed treatment regimens by extending cycle length in patients yet responding to established therapies with ICI-based combinations, holding one ICI or even both drugs (ICI/ICI or ICI/TKI). The survey results and the investigator discussion contributed to raise the awareness of the uncertainties about the interplay of ICI and SARS$\mathrm{CoV}-2$ infection, already discussed by oncologists 
since the beginning of the pandemic [100], but only partially supported by original data $[101,102]$.

The further survey, by Staehler et al., with two different publications about clinical outcomes and financial toxicity, interviewed 539 patients, offering a patient-oriented perspective on treatment preferences and anxiety levels generated by the pandemic $[94,95]$. The investigators demonstrated that, besides high anxiety regarding COVID-19, most patients preferred not to defer therapy (51\%), especially those receiving ICI immunotherapy. Furthermore, considering patients with localized disease (40\% of cases, with active surveillance or in follow-up after surgery), the majority of subjects were unwilling to delay radiological assessments planned for their follow-up/surveillance program, despite their frequent perception of higher risk of COVID-19 infection than the general population [94]. The financial burden of COVID-19 was also assessed through a validated comprehensive score for financial toxicity (COST) patient-reported outcome measure [95]: the collected responses highlighted the severe financial impact of the pandemic in patients with RCC in the reality of the United States, where systemic therapies have one of the highest co-pays for patients [103].

Among the narrative papers, Ivanyi et al. summarized the consensus recommendations by the Interdisciplinary working group on renal tumors (IAG-N) of the German Cancer Society for the systemic treatment of advanced/metastatic RCC in the context of the SARS-CoV-2 pandemic. The authors, beyond patient-based risk-benefit considerations, identified the poor prognosis patients, according to the International Metastatic Database Consortium (IMDC) model, as a category wherein the clear harm of the metastatic RCC and the oncological efficacy of ICI overweight the risk of pandemic associated concerns, thus strengthening the recommendation towards the choice of immunotherapy-based combinations [96].

A urological consensus outlined relatively conservative attitudes about the surgical approach during the pandemic, preferring active surveillance in $\mathrm{cT} 1 \mathrm{a}$ tumors, suggesting postponed surgery until 90 days in selected T1b-T2a cases, and encouraging minimally invasive surgery aimed at early hospital discharge for cT3 or worse tumors. Furthermore, the authors expressed a negative opinion about cytoreduction in metastatic RCC, both for low-risk oligometastatic patients and poor-intermediate categories, suggesting primary systemic therapy and considering postponed cytoreduction in good responders [97].
Mihalopoulos and co-authors discussed the kidney's role in facilitating routes for SARS-CoV-2 entry in cells, leading to increased virulence and clinical manifestation in RCC, showing an overview of the primary signaling targets of viral infection and their association with renal disease. Their hypothesisgenerating reflections led to the proposal of a schema for the current therapeutic management (blocking ACE-2 receptor pathway and hence viral internalization into host cells) and the suggestion for prevention strategies for COVID-19 by controlling inflammation and immunosuppression, and consequently augmenting cell response to virulence, in patients with underlying renal disease [98].

Finally, authors from the Johns Hopkins University provided a treatment algorithm for advanced RCC systemic therapy, suggesting off-label tailored approaches, especially in patients with an intermediate risk of developing irAEs (such as patients with psoriasis, coeliac disease, or type 1 diabetes mellitus), namely upfront axitinib monotherapy followed by addition of pembrolizumab when COVID-19 risk subsides. Treatment break with serial follow-up imaging was also suggested in cases with a complete or deep partial response after one year of ICI treatment, or even in non-progressive disease after two years of therapy [99].

\section{DISCUSSION}

Considering the high unmet need for data allowing evidence-based choices for genitourinary cancer patients (and RCC ones in particular) in the COVID19 era, we tried to provide all the available findings with the present systematic work. Our aim was collecting elements for supporting reasonable recommendations about hot topics of interest in this field, providing useful indications to manage everyday situations from the diagnosis to the systemic treatment of renal tumors during the pandemic. Nevertheless, our systematic search evidenced an evident prevalence of narrative publications (69\%), mainly constituted by review works, suggesting the inevitable question about what evidence has been reviewed. At the end of the day, the only original data about renal cancer and COVID-19 was constituted by a small retrospective case series and two surveys, the latters providing either the patients' or the physicians' viewpoint [92-94]. Also, in other genitourinary tumors, a single prospective analysis was reported on prostate cancer, and the few retrospective study findings on prostate and urothelial cancers were not always consistent 
with each other $[41,42,44,45,49,50,56,60,64$, $65,67,69,79]$. With this significant limitation, in the following paragraphs, we are going to provide our viewpoint and personal recommendations for managing the most frequent challenges in the diagnosis and treatment of renal cancer during the COVID-19 pandemic.

\section{RCC diagnosis: Impact of delay on epidemiology}

RCC is not a tumor susceptible to routine screening in an unselected population. Early-stage disease often represents an incidental finding during routine ultrasound (US) assessments, performed for other indications, and frequently lacks symptoms. The widespread use of abdominal US, performed to investigate mild functional symptoms, allows the occasional diagnosis of small renal masses, usually susceptible to radical treatment [104].

During the first outbreak of COVID-19, at the beginning of 2019 and in the subsequent months, the general population's main feeling regarding hospitals was dominated by fear. Adult individuals, especially the elderly, were terrified about going to the hospital, being visited by a physician, staying in crowded waiting rooms [105]. Therefore, most individuals avoided unnecessary procedures, preventing the occasional finding of small asymptomatic masses, and possibly ignoring or underestimating the occurrence of symptoms and signs until their clear clinical manifestation. Together with this first impact on the possible delayed diagnosis of RCC, patients who were following a program of active surveillance for cystic or solid renal lesions, or a follow-up program after radical surgery of early renal cancer, often postponed their periodic assessment, frequently irrespectively of their willingness, during the lockdown [93]. The organization of diagnostic procedures during COVID-19 outbreaks was challenging in certain realities. Screening swabs performed while approaching renal masses frequently revealed asymptomatic positive cases for SARS-CoV-2, triggering quarantine measures, and blocking the diagnostic path before reaching a diagnosis. Finally, the interruption of surgical activities during severe COVID-19 outbreaks in our Country affected the number of patients undergoing resection of previously identified renal masses, preventing their surgical curability and generating a waiting gap during which the disease was likely to progress. Because of all these phenomena, the current temporary reduction of limited-stage RCC diagnosis might lead to an increase of advanced diagnoses and metastatic cases, transiently modifying the disease's epidemiologic situation in the next months and years [106]. In this situation of an expected increase of metastatic RCC numbers, given the recent innovations introduced in the systemic treatment scenario, creating new treatment algorithms (and rethinking plans for their financial sustainability) will be even more crucial for the future management of the advanced disease [107].

\section{Therapy of small renal masses: Surveillance or treatment during the pandemic}

Some authors extrapolated observational data on treatment delays to estimate hazard ratios for diagnostic delay in the most common cancer types, assuming that cancers with low 5-year survival rates might have been less affected by diagnostic delay than cancers with high survival rates [108]. Today, few experimental data exist on the real consequences of diagnostic delay in RCC. Recently, Srivastava et al. reported the data from 29,746 patients who underwent partial or radical nephrectomy. Based on their analysis, delaying surgery $>3$ months after diagnosis did not confer pT3a upstaging risk among cT1b $(\mathrm{OR}=0.90 ; 95 \%$ CI: $0.77-1.05, p=0.170)$, cT2a $(\mathrm{OR}=0.90 ; 95 \%$ CI: $0.69-1.19, p=0.454)$, or cT2b lesions $(\mathrm{OR}=0.96$; 95\% CI: $0.62-1.51$, $p=0.873$ ) [109]. These data are undoubtedly comforting towards the possibility of delayed detection of small renal masses due to the COVID-19 emergency.

However, before planning to intentional delaying surgery due to COVID-19 after the finding of a renal lesion, the availability of routine hospital resources (i.e., radiologic assessment) should be carefully evaluated, preventing the risk of being unable to offer proper surveillance in the case of prolonged outbreaks. Current data support oncologic safety for active surveillance in managing clinically localized renal masses, in particular among elderly and/or patients with comorbidities [110]. Compared to a single surgical session, timely active surveillance may be more difficult to warrant during emergency and organizational unrest. The patients' compliance must also be assessed, especially concerning their anxiety levels surrounding COVID-19 [93].

\section{Systemic treatment with vascular endothelial growth factor receptors (VEGFR) tyrosine kinase inhibitors (TKIs): Possible benefits also for COVID-19?}

The backbone of the systemic treatment for advanced or metastatic RCC (mRCC) is still currently 
represented by VEGFR-TKIs. Considering the mechanism of action of these agents, possible benefits could be expected even against COVID-19 pathogenesis, especially with regard to COVID-19 pneumonia. Indeed, the expression of the ligand vascular endothelial growth factor (VEGF) is induced by hypoxia through activation of the hypoxia-inducible factor (HIF)-1 pathway [111]. VEGF participates in lung inflammation and induces vascular permeability in SARS-CoV-2-infected lung tissues, resulting in plasma extravasation and pulmonary edema, further increasing tissue hypoxia [112, 113]. VEGF levels in patients with severe COVID-19 are markedly elevated, and VEGF-induced vascular effects, such as vascular disorganization and endothelial cell proliferation, have been found in lung tissues with COVID-19 pneumonia $[114,115]$. Interestingly, favorable preliminary outcomes have been reported from the experimental therapeutic approach with the antiVEGF monoclonal antibody bevacizumab in patients with severe COVID-19 [116].

Considering this evidence, the systemic treatment with anti-VEGFR agents in mRCC patients during the pandemic does not imply particular concerns, possibly contributing to counteracting the pathogenesis of COVID-19 beyond the anticancer therapeutic employment.

\section{Systemic treatment with immune checkpoint inhibitors: The two-faced Gianus}

Compared to systemic treatment with VEGFRTKIs, the most recent immune-based therapies (either monotherapy or combinations) have raised several controversies in the COVID-19 era. It is currently clear that, for most patients, first-line treatment should be represented by an ICI-based combination [107]. Nevertheless, some authors raised the issue of possible additional risk of immune-related toxicity in the case of concomitant SARS-CoV-2 infection, given the similarities between ICI-related pneumonitis and COVID-pneumonia and the possible triggering of cytokine release in both cases [117, 118]. The issue is challenging, as several aspects should be considered, from the potential interference between COVID-19 pathogenesis and immune checkpoint blockade, to the likely pleiotropic functions of immune checkpoints in modulating the different phases of the immune response to SARSCoV-2 infection [100].

The other side of the coin, regarding ICI, is indeed represented by their potential therapeutic value beyond cancer treatment. Their capacity to restore cellular immunocompetence may be exploited, particularly within the initial phase of the COVID-19 illness, to modulate the immune response to SarsCov-2 infection in the viremic phase, influencing the activity of $\mathrm{T}$ cells, modulating their cytokine production, and avoiding progression into cytokine storm, thus preventing the evolution in severe forms of COVID-19 [119]. Based on the mechanisms of action of ICIs and the current evidence, it has been suggested by several authors that ICIs not only can be safely administered to cancer patients also during the pandemic, but they might even be beneficial in COVID-19-positive cancer patients by exerting their immune-stimulating action $[120,121]$.

Beyond these two-faced considerations, in the current lack of data for either detrimental or beneficial effects of ICI during SARS-CoV-2 infection, the principle of caution should be used.

\section{Management of mRCC patients with SARS-CoV-2 positive swab: The risk-benefit challenge}

Except for patients with favorable IMDC score, possible candidates to active surveillance and easy treatment delay or discontinuation in the case of COVID-19 occurrence, it is not always possible delaying systemic treatment for metastatic RCC patients. Basing on our personal experience with these patients during the pandemic in our Country, we are going to propose two different algorithms based on the timing of COVID-19 occurrence:

1) Patients with a new diagnosis of metastatic RCC, in the case of COVID-19 occurrence before therapy initiation, should be first treated for symptomatic COVID-19, delaying the initiation of cancer therapy after complete or at least partial resolution of the acute clinical course of the disease. When the symptomatic phase of the infection is improved, with the absence of fever $\geq 38^{\circ}$ and respiratory impairment, irrespective of the swab positivity's persistency, cancer treatment should be initiated to avoid further progression of the oncological disease. Provided the absence of pneumonitis at the CT scan, ICI-based therapies must be the preferred first-line approach for intermediate and poor-risk patients according to the IMDC model [122]. In the case of persistent interstitial pneumonia at the CT scan, after resolving the respiratory impairment, cancer 
treatment could be initiated with VEGFR-TKI alone, postponing the combination with ICI and planning a bi-monthly radiological follow-up with high-resolution thoracic CT. At the resolution of interstitial pneumonitis, (deferred) anti-PD-1 ICI must be associated (i.e., pembrolizumab with axitinib or nivolumab with cabozantinib) for patients with intermediate or poor-risk disease, depending on each country drugs availability.

2) Patients undergoing systemic treatment for metastatic RCC, in the case of COVID-19 occurrence during ICI, should temporarily discontinue cancer therapy until resolution of the acute clinical symptoms of the disease. In the case of VEGFR-TKI monotherapy, when severe symptoms of COVID-19 are improved, irrespective of the swab positivity, cancer treatment should be quickly resumed to avoid progression of the oncological disease. In the case of interstitial pneumonitis at the CT scan, even in asymptomatic patients, ICI-based therapies should be cautiously discontinued until radiological resolution.

\section{Research advances in RCC: Hints from COVID-19}

With the researchers' typical attitude, renal cancer experts from all over the world took the hints suggested by COVID-19 etiopathogenesis to further explore the underlying mechanisms behind renal carcinogenesis and tumor progression. Interestingly, angiotensin-converting enzyme 2 (ACE2), the surface protein serving as a functional receptor for SARS-CoV-2, was recently identified as a prognostic factor for RCC [123]. This research analyzed the difference in the survival rate according to ACE2 expression levels in 31 types of cancer by using The Cancer Genome Atlas (TCGA) dataset. The survival curves demonstrated that in clear cell RCC (as well as in the case of uveal melanoma and prostate adenocarcinoma) high ACE2 expression was related to a good prognosis. ACE inhibitors, widely used as therapeutic agents for hypertension treatment, are reported to upregulate ACE2 receptor expression [124]. Therefore, it was assumed that the use of ACE inhibitors, by increasing ACE2 expression levels, may improve survival rates in RCC patients.

Once again, the black side of the coin is that high expression of ACE2, found in RCC, may be related to high susceptibility to coronaviruses (CoVs) infection.
Another research group investigated molecular profiling data of the various proteins required for the entry of the CoVs in normal tissues and cancer tissues, confirming that renal tumors exhibited the highest expression of ACE2 receptor. DPP4, ANPEP, and ENPEP RNA expression were also elevated in RCC, and these molecules have also been proposed as co-receptors to initiate SARS-CoV-2 and other coronavirus infections. The authors suggested that, because of such molecular expression, the infection risk could be higher in RCC patients; furthermore, based on the evidence that CoVs can directly infect the human kidney, it was hypothesized that the renal tumor could act as a viral reservoir, distributing the viral load. Finally, they also explored the possibility that CoVs' receptors are involved in modulating tumor immunity, demonstrating their association with high immune infiltration, immunosuppression markers, and $\mathrm{T}$ cell exhaustion [125].

As a further step on this intriguing road, ACE2 was very recently found to correlate with immunotherapy response positively, and its upregulation was associated with increased antitumor immune signatures and PD-L1 expression [126]. Four cancer cohorts receiving immune checkpoint blockade therapy were tested: the high-ACE2-expression-level tumors displayed a higher response rate than the low-ACE2-expression-level tumors (in particular, the objective response rate was $40 \%$ versus $20 \%$ in the renal cell carcinoma cohort). These results suggest that the ACE2 expression could be a positive predictor for anti-PD-1/PD-L1 immunotherapy response.

\section{CONCLUSIONS}

Summarizing the evidence about RCC and COVID-19, we are going to propose the following conclusive highlights:

a) The literature offers more comments and opinions, than original data, on genitourinary cancers, with most publications regarding prostate cancer and only a few studies on RCC patients.

b) An impact of the delayed diagnosis on RCC epidemiology could be foreseen, with an increase in RCC cases diagnosed in the metastatic setting and possible consequences in sustainability.

c) The proper therapeutic choices for patients with small renal masses should be carefully evaluated case by case, in order to avoid negative effects on long-term survival rates. 
d) The controversial interaction between immune checkpoint blockade and COVID-19 pathogenesis is more hypothetical than evidence-based, suggesting prioritizing the concept that immunotherapy improves overall survival in $\mathrm{mRCC}$ patients, and the risk-benefit ratio is likely almost always in favor of avoiding replacements.

e) Too many advanced cancer patients, including RCC ones, receive treatments which won't have any impact on their survival [127]; thus, before planning any treatments for a metastatic patint, a honest and accurate evaluation of the cost/benefit ratio of each considered treatment option should be performed, maintaining ethics at the forefront of our decision making process [127, 128].

f) SARS-CoV-2 swab positivity should not prevent the continuation of the ongoing active anticancer therapy in asymptomatic cases or if the acute disease is solved (provided that organizational problems for the oncology unit access can be bypassed with domiciliary prescription or hospitalization in COVID-wards).

Finally, the challenges generated by the SARS$\mathrm{CoV}-2$ pandemic also had a positive side, triggering the investigations and opening new questions about molecular and immunological mechanisms that were previously neglected.

\section{ACKNOWLEDGMENTS}

The authors have no acknowledgments.

\section{FUNDING}

The authors report no funding.

\section{AUTHOR CONTRIBUTIONS}

Both authors have made substantial contributions to the work and the article writing, approved the final version of the manuscript, and agreed to be accountable for its accuracy and integrity.

\section{CONFLICTS OF INTEREST}

Melissa Bersanelli received research funding (institutional) from Roche, Pfizer, Seqirus UK, AstraZeneca, BMS, Novartis, and Sanofi; she also received honoraria (personal fees) for advisory role, copyright transfer, consultancies, and as a speaker at scientific events by Sciclone Pharmaceuticals, BMS, AstraZeneca, Pierre-Fabre, Novartis and Pfizer. Camillo Porta acted as a paid Consultant and/ or speaker for MSD, BMS, AstraZeneca, Ipsen, EUSA, Eisai, Merck, Novartis, General Electric and Angelini; he also is a protocol steering committee member for Eisai, EUSA and BMS and acted as an Expert Testimony for Pfizer and EUSA.

\section{REFERENCES}

[1] Emanuel EJ, Persad G, Upshur R, Thome B, Parker M, Glickman A, Zhang C, Boyle C, Smith M, Phillips JP. Fair Allocation of Scarce Medical Resources in the Time of Covid-19. N Engl J Med. 2020;382(21):2049-55.

[2] Rosenbaum L. Facing Covid-19 in Italy - Ethics, Logistics, and Therapeutics on the Epidemic's Front Line. N Engl J Med. 2020;382(20):1873-5.

[3] Schrag D, Hershman DL, Basch E. Oncology Practice During the COVID-19 Pandemic. JAMA. 2020;323(20): 2005-6.

[4] Yang K, Sheng Y, Huang C, Jin Y, Xiong N, Jiang K, Lu H, Liu J, Yang J, Dong Y, Pan D, Shu C, Li J, Wei J, Huang Y, Peng L, Wu M, Zhang R, Wu B, Li Y, Cai L, Li G, Zhang T, Wu G. Clinical characteristics, outcomes, and risk factors for mortality in patients with cancer and COVID-19 in Hubei, China: a multicentre, retrospective, cohort study. Lancet Oncol. 2020;21(7):904-13.

[5] Kuderer NM, Choueiri TK, Shah DP, Shyr Y, Rubinstein SM, Rivera DR, Shete S, Hsu CY, Desai A, de Lima Lopes G Jr, Grivas P, Painter CA, Peters S, Thompson MA, Bakouny Z, Batist G, Bekaii-Saab T, Bilen MA, Bouganim N, Larroya MB, Castellano D, Del Prete SA, Doroshow DB, Egan PC, Elkrief A, Farmakiotis D, Flora D, Galsky MD, Glover MJ, Griffiths EA, Gulati AP, Gupta S, Hafez N, Halfdanarson TR, Hawley JE, Hsu E, Kasi A, Khaki AR, Lemmon CA, Lewis C, Logan B, Masters T, McKay RR, Mesa RA, Morgans AK, Mulcahy MF, Panagiotou OA, Peddi P, Pennell NA, Reynolds K, Rosen LR, Rosovsky R, Salazar M, Schmidt A, Shah SA, Shaya JA, Steinharter J, Stockerl-Goldstein KE, Subbiah S, Vinh DC, Wehbe FH, Weissmann LB, Wu JT, Wulff-Burchfield E, Xie Z, Yeh A, Yu PP, Zhou AY, Zubiri L, Mishra S, Lyman GH, Rini BI, Warner JL; COVID-19 and Cancer Consortium. Clinical Impact of COVID-19 on Patients With Cancer (CCC19): A Cohort Study. Lancet. 2020;395(10241):1907-18.

[6] Dai M, Liu D, Liu M, Zhou F, Li G, Chen Z, Zhang Z, You H, Wu M, Zheng Q, Xiong Y, Xiong H, Wang C, Chen C, Xiong F, Zhang Y, Peng Y, Ge S, Zhen B, Yu T, Wang L, Wang H, Liu Y, Chen Y, Mei J, Gao X, Li Z, Gan L, He C, Li Z, Shi Y, Qi Y, Yang J, Tenen DG, Chai L, Mucci LA, Santillana M, Cai H. Patients with Cancer Appear More Vulnerable to SARS-CoV-2: A Multicenter Study during the COVID-19 Outbreak. Cancer Discov. 2020;10(6):783-91.

[7] Albiges L, Stéphanie Foulon S, Arnaud Bayle A, Bertrand Gachot B, Fanny Pommeret F, Christophe Willekens C, Annabelle Stoclin A, Mansouria Merad M, Frank Griscelli F, Ludovic Lacroix L, Florence Netzer F, Thomas Hueso T, Corinne Balleyguier C, Samy Ammari S, Emeline Colomba E, Giulia Baciarello G, Audrey Perret A, Antoine Hollebecque A, Julien Hadoux J, Jean-Marie Michot JM, 
Chaput N, Veronique Saada V, Mathilde Hauchecorne M, Jean-Baptiste Micol JB, Roger Sun R, Dominique Valteau-Couanet D, Fabrice André F, Florian Scotte F, Besse B, Soria JC, Barlesi F. Determinants of the outcomes of patients with cancer infected with SARS-CoV-2: results from the Gustave Roussy cohort. Nature Cancer. 2020;1:965-75.

[8] DeBoer RJ, Fadelu TA, Shulman LN, Van Loon K. Applying Lessons Learned From Low-Resource Settings to Prioritize Cancer Care in a Pandemic. JAMA Oncol. 2020; 6(9):1429-33.

[9] Moher D, Liberati A, Tetzlaff J, Altman DG, the PRISMA Group. Preferred Reporting Items for Systematic Reviews and Meta-Analyses: The PRISMA Statement. PlosOne; 2009 [updated 2009 July 21 ; cited 2021 January 12]. Available from: http://prisma-statement.org/

[10] Gillessen S, Powles T. Advice Regarding Systemic Therapy in Patients with Urological Cancers During the COVID-19 Pandemic. Eur Urol. 2020;77(6):667-8. doi: 10.1016/j.eururo.2020.03.026

[11] Di Lorenzo G. Eur Urol. Re: Silke Gillessen Sommer, Thomas Powles. Advice for Medical Oncology Care of Urological Cancer Patients During the COVID-19 Pandemic. Eur Urol 2020;78:e2-3: Is It Always Correct to Continue Androgen Receptor Signaling Inhibitors in the COVID-19 Era? Eur Urol. 2020;78(1):e10-e11. doi: 10. 1016/j.eururo.2020.04.030

[12] Mian BM, Siddiqui S, Ahmad AE. Management of urologic cancers during the pandemic and potential impact of treatment deferrals on outcomes. Urol Oncol. 2020:S1078-1439(20)30484-1. doi:10.1016/j.urolonc.20 20.10.013

[13] Darlington CD, Mammen RJ, Mammen KJ. COVID-19 and its impact on genitourinary malignancies. Indian $\mathrm{J}$ Urol. 2020;36(3):163-70. doi: 10.4103/iju.IJU_167_20

[14] Wallis CJD, Catto JWF, Finelli A, Glaser AW, Gore JL, Loeb S, Morgan TM, Morgans AK, Mottet N, Neal R, O'Brien T, Odisho AY, Powles T, Skolarus TA, Smith AB, Szabados B, Klaassen Z, Spratt DE. The Impact of the COVID-19 Pandemic on Genitourinary Cancer Care: Reenvisioning the Future. Eur Urol. 2020;78(5):731-42. doi: 10.1016/j.eururo.2020.08.030

[15] Katims AB, Razdan S, Eilender BM, Wiklund P, Tewari AK, Kyprianou N, Badani KK, Mehrazin R. Urologic oncology practice during COVID-19 pandemic: A systematic review on what can be deferrable vs. nondeferrable. Urol Oncol. 2020;38(10):783-92. doi:10.1016/j.urolonc. 2020.06.028

[16] Tachibana I, Ferguson EL, Mahenthiran A, Natarajan JP, Masterson TA, Bahler CD, Sundaram CP. Delaying Cancer Cases in Urology during COVID-19: Review of the Literature. J Urol. 2020;204(5):926-33. doi: 10.1097/ JU.0000000000001288

[17] Rodríguez-Covarrubias F, Castillejos-Molina RA, AutránGómez AM. Summary and considerations in genitourinary cancer patient care during the COVID-19 Pandemic. Int Braz J Urol. 2020; 46(suppl.1):98-103. doi: 10.1590/ S1677-5538.IBJU.2020.S115

[18] Simonato A, Giannarini G, Abrate A, Bartoletti R, Crestani A, De Nunzio C, Gregori A, Liguori G, Novara G, Pavan N, Trombetta C, Tubaro A, Porpiglia F, Ficarra V; Research Urology Network (RUN). Clinical pathways for urology patients during the COVID-19 pandemic. Minerva Urol Nefrol. 2020;72(3):376-83. doi: 10.23736/S03932249.20.03861-8
[19] Fizazi K. Therapeutic options for genitourinary cancers during the epidemic period of COVID-19. Considerations in the Triage of Urologic Surgeries During the COVID-19 Pandemic. Bull Cancer. 2020;107(4): 395-7. doi: 10.1016/j.bulcan.2020.03.003. Epub 2020 Mar 27.

[20] Stensland KD, Morgan TM, Moinzadeh A, Lee CT, Briganti A, Catto JWF, Canes D. Considerations in the Triage of Urologic Surgeries During the COVID-19 Pandemic. Eur Urol. 2020;77(6):663-6. doi: 10.1016/j.eururo. 2020.03.027

[21] Oderda M, Roupret M, Marra G, Merseburger AS, Oderda G, Falcone M, Ceruti C, Shariat SF, Gontero P. The Impact of COVID-19 Outbreak on Uro-oncological Practice Across Europe: Which Burden of Activity Are We Facing Ahead? Eur Urol. 2020;78(1):124-6. doi: 10.1016/j.eururo.2020.04.036

[22] Waterhouse JV, Hull JH, Linch M. Corticosteroids for Urological Cancer Care During Coronavirus Disease 2019. Treat or Not to Treat? Eur Urol. 2020;78(1):9-10. doi: 10.1016/j.eururo.2020.04.027

[23] Rodler S, Apfelbeck M, Stief C, Heinemann V, Casuscelli J. Lessons from the coronavirus disease 2019 pandemic: Will virtual patient management reshape urooncology in Germany? Eur J Cancer. 2020;132:136-40. doi: 10.1016/j.ejca.2020.04.003

[24] Desouky E. Impact of COVID-19 on Urologists: Learning on the Go. Eur Urol Focus. 2020;6(5):1132-4. doi: 10.1016/j.euf.2020.04.008

[25] Wallis CJD, Novara G, Marandino L, Bex A, Kamat AM, Karnes RJ, Morgan TM, Mottet N, Gillessen S, Bossi A, Roupret M, Powles T, Necchi A, Catto JWF, Klaassen Z. Risks from Deferring Treatment for Genitourinary Cancers: A Collaborative Review to Aid Triage and Management During the COVID-19 Pandemic. Eur Urol. 2020;78(1):29-42. doi: 10.1016/j.eururo.2020.04.063

[26] Narain TA, Gautam G, Seth A, Panwar VK, Rawal S, Dhar P, Talwar HS, Singh A, Jaipuria J, Mittal A. Uro-oncology in times of COVID-19: The available evidence and recommendations in the Indian scenario. Indian $\mathrm{J}$ Cancer 2020;57(2):129-38. doi: 10.4103/ijc.IJC_356_20

[27] Szabados B, Abu-Ghanem Y, Grant M, Choy J, Bex A, Powles T. Clinical Characteristics and Outcome for Four SARS-CoV-2-infected Cancer Patients Treated with Immune Checkpoint Inhibitors. Eur Urol. 2020;78(2):27680. doi: 10.1016/j.eururo.2020.05.024

[28] Shah P, Kim FJ, Mian BM. Genitourinary cancer management during a severe pandemic: Utility of rapid communication tools and evidence-based guidelines. BJUI Compass. 2020;1(2):45-59. doi: 10.1002/bco2.18

[29] Ambrosini F, Di Stasio A, Mantica G, Cavallone B, Serao A. COVID-19 pandemic and uro-oncology follow-up: A "virtual" multidisciplinary team strategy and patients" satisfaction assessment. Arch Ital Urol Androl. 2020;92(2). doi: 10.4081/aiua.2020.2.78

[30] Lundon DJ, Kelly BD, Shukla D, Bolton DM, Wiklund P, Tewari A. A Decision Aide for the Risk Stratification of GU Cancer Patients at Risk of SARS-CoV-2 Infection, COVID-19 Related Hospitalization, Intubation, and Mortality. J Clin Med. 2020;9(9):2799. doi: $10.3390 / \mathrm{jcm} 9092799$

[31] Quarto G, Grimaldi G, Castaldo L, Izzo A, Muscariello R, De Sicato S, Franzese D, Crocerossa F, Del Prete P, Carbonara U, Autorino R, Perdonà S. Avoiding disruption of timely surgical management of genitourinary cancers 
during the early phase of the COVID-19 pandemic. BJU Int. 2020;126(4):425-7. doi: 10.1111/bju.15174

[32] Amparore D, Campi R, Checcucci E, Sessa F, Pecoraro A, Minervini A, Fiori C, Ficarra V, Novara G, Serni S, Porpiglia F. Forecasting the Future of Urology Practice: A Comprehensive Review of the Recommendations by International and European Associations on Priority Procedures During the COVID-19 Pandemic. Eur Urol Focus. 2020;6(5):1032-48. doi: 10.1016/j.euf.2020.05.007

[33] Tinay I, Ozden E, Suer E, Bozkurt O, Izol V, Sahin B, Turkeri L. The Early Impact of COVID-19 Pandemic on Surgical Urologic Oncology Practice in Turkey: MultiInstitutional Experience From Different Geographic Areas. Urology. 2020;142:29-31. doi: 10.1016/j.urology. 2020.05.016

[34] Roscigno M, Naspro R, Piccichè A, Muttin F, Angiolilli D, Deiana G, Pezzoli F, Da Pozzo LF. A Snapshot from the Department of Urology in Bergamo Evaluating the Timeline of the SARS-CoV-2 Outbreak: Which Patients Are We Missing? Eur Urol Focus. 2020;6(5):1120-3. doi: 10.1016/j.euf.2020.05.022

[35] Heldwein FL, Loeb S, Wroclawski ML, Sridhar AN, Carneiro A, Lima FS, Teoh JY. A Systematic Review on Guidelines and Recommendations for Urology Standard of Care During the COVID-19 Pandemic. Eur Urol Focus. 2020;6(5):1070-85. doi: 10.1016/j.euf.2020.05.020

[36] Rosenzweig B, Bex A, Dotan ZA, Frydenberg M, Klotz L, Lotan Y, Schulman CC, Tsaur I, Ramon J. Trends in urologic oncology clinical practice and medical education under COVID-19 pandemic: An international survey of senior clinical and academic urologists. Urol Oncol. 2020; 38(12):929.e1-929.e10. doi: 10.1016/j.urolonc.2020. 09.015

[37] Harke NN, Radtke JP, Hadaschik BA, Bach C, Berger FP, Blana A, Borgmann H, Distler FA, Edeling S, Egner T, Engels CL, Farzat M, Haese A, Hein R, Kuczyk MA, Manseck A, Moritz R, Musch M, Peters I, Pokupic S, Rocco B, Schneider A, Schumann A, Schwentner C, Sighinolfi CM, Buse S, Stolzenburg JU, Truß MC, Waldner M, Wülfing C, Zimmermanns V, Witt JH, Wagner C. To defer or not to defer? A German longitudinal multicentric assessment of clinical practice in urology during the COVID-19 pandemic. PLoS One. 2020;15(9):e0239027. doi: 10.1371/journal.pone.0239027

[38] Heyes SM, Bond MJ. Pathways to psychological wellbeing for patients with bladder cancer and their partners-in-care. Eur J Oncol Nurs. 2020;46:101757. doi: 10.1016/j.ejon.2020.101757

[39] Esperto F, Pang KH, Albisinni S, Papalia R, Scarpa RM. Bladder Cancer at the time of COVID-19 Outbreak. Int Braz J Urol. 2020;46(suppl.1):62-8. doi: 10.1590/S16775538.IBJU.2020.S107

[40] Marandino L, Di Maio M, Procopio G, Cinieri S, Beretta GD, Necchi A. The Shifting Landscape of Genitourinary Oncology During the COVID-19 Pandemic and how Italian Oncologists Reacted: Results from a National Survey. Eur Urol. 2020;78(1):e27-e35. doi: 10.1016/j.eururo. 2020.04.004

[41] Lenfant L, Seisen T, Loriot Y, Rouprêt M. Adjustments in the Use of Intravesical Instillations of Bacillus CalmetteGuerin for High-risk Non-muscle-invasive Bladder Cancer During the COVID-19 Pandemic. Eur Urol. 2020; 78(1):1-3. doi: 10.1016/j.eururo.2020.04.039

[42] Patel K, Choudhury A, Hoskin P, Varughese M, James $\mathrm{N}$, Huddart R, Birtle A. Clinical Guidance for the
Management of Patients with Urothelial Cancers During the COVID-19 Pandemic - Rapid Review. Clin Oncol (R Coll Radiol). 2020;32(6):347-53. doi: 10.1016/ j.clon.2020.04.005

[43] Busetto GM, Porreca A, Del Giudice F, Maggi M, D'Agostino D, Romagnoli D, Musi G, Lucarelli G, Palmer K, Colonna di Paliano A, Muto M, Hurle R, Terracciano D, de Cobelli O, Sciarra A, De Berardinis E, Ferro M. SARS$\mathrm{CoV}-2$ Infection and High-Risk Non-Muscle-Invasive Bladder Cancer: Are There Any Common Features? Urol Int. 2020;104(7-8):510-22. doi: 10.1159/000509065

[44] Hegarty PK, Sfakianos JP, Giannarini G, DiNardo AR, Kamat AM. COVID-19 and Bacillus Calmette-Guerin: What is the Link? Eur Urol Oncol. 2020;3(3):259-61. doi: 10.1016/j.euo.2020.04.001

[45] Wang T, Liu S, Joseph T, Lyou Y. Managing Bladder Cancer Care during the COVID-19 Pandemic Using a Team-Based Approach. J Clin Med. 2020;9(5):1574. doi: 10.3390/jcm9051574

[46] Almassi N, Mulhall JP, Funt SA, Sheinfeld J. 'Case of the Month' from Memorial Sloan Kettering Cancer Center, New York, NY, USA: managing newly diagnosed metastatic testicular germ cell tumour in a COVID19-positive patient. BJU Int. 2020;126(3):333-5. doi: 10.1111/bju.15157

[47] Nappi L, Ottaviano M, Rescigno P, Tortora M, Banna GL, Baciarello G, Basso U, Canil C, Cavo A, Cossu Rocca M, Czaykowski P, De Giorgi U, Garcia Del Muro X, Di Napoli M, Fornarini G, Gietema JA, Heng DYC, Hotte SJ, Kollmannsberger C, Maruzzo M, Messina C, Morelli F, Mulder S, Nichols C, Nolè F, Oing C, Sava T, Secondino S, Simone G, Soulieres D, Vincenzi B, Zucali PA, De Placido S, Palmieri G; Italian Germ Cell Cancer Group (IGG); ERN-EURACAN Domain G3; Genitourinary Medical Oncologists of Canada (GUMOC). Management of Germ Cell Tumors During the Outbreak of the Novel Coronavirus Disease-19 Pandemic: A Survey of International Expertise Centers. Oncologist. 2020;25(10):e1509-e1515. doi: 10.1634/theoncologist.2020-0420

[48] Fantin JPP, Facio MFW, Spessoto ACN, Spessoto LCF, Facio Junior FN. Does androgen deprivation therapy in patients with prostate cancer protect from COVID-19? Rev Assoc Med Bras (1992). 2020;66(10):1314-5. doi: 10.1590/1806-9282.66.10.1314

[49] Mou R, Jin X, Li W, Wu M, Liu X, Liu Z, Guo S, Li X, Jia Y. Prostate cancer: a risk factor for COVID19 in males? A protocol for systematic review and meta analysis. Medicine (Baltimore). 2020;99(43):e22591. doi: 10.1097/MD.0000000000022591

[50] Gomella LG. COVID-19 and The Prostate Cancer Connection. Can J Urol. 2020;27(5):10346.

[51] Hoffman KE. Wait and Hurry Up: Radiation Therapy for Prostate Cancer During the COVID-19 Pandemic. Int J Radiat Oncol Biol Phys. 2020;108(2):340. doi: 10.1016/j.ijrobp.2020.07.012

[52] Mohamad O, Roach M 3rd. Delaying Dilemmas: Coronavirus Complications Impacting the Management of Prostate Cancer. Int J Radiat Oncol Biol Phys. 2020; 108(2):337. doi: 10.1016/j.ijrobp.2020.07.009

[53] Dee EC, Mahal BA, Arega MA, D'Amico AV, Mouw KW, Nguyen PL, Muralidhar V. Relative Timing of Radiotherapy and Androgen Deprivation for Prostate Cancer and Implications for Treatment During the COVID-19 Pandemic. JAMA Oncol. 2020;6(10):1630-2. doi:10.1001/ jamaoncol.2020.3545 
[54] Obek C, Doganca T, Argun OB, Kural AR. Management of prostate cancer patients during COVID-19 pandemic. Prostate Cancer Prostatic Dis. 2020;23(3):398-406. doi: 10.1038/s41391-020-0258-7

[55] Patel VG, Zhong X, Liaw B, Tremblay D, Tsao CK, Galsky MD, Oh WK. Does androgen deprivation therapy protect against severe complications from COVID-19? Ann Oncol. 2020;31(10):1419-20. doi: 10.1016/j.annonc. 2020.06.023

[56] Chakravarty D, Nair SS, Hammouda N, Ratnani P, Gharib Y, Wagaskar V, Mohamed N, Lundon D, Dovey Z, Kyprianou N, Tewari AK. Sex differences in SARS-CoV-2 infection rates and the potential link to prostate cancer. Commun Biol. 2020;3(1):374. doi: 10.1038/s42003-0201088-9

[57] Koskinen M, Carpen O, Honkanen V, Seppänen MRJ, Miettinen PJ, Tuominen JA, Raivio T. Androgen deprivation and SARS-CoV-2 in men with prostate cancer. Ann Oncol. 2020;31(10):1417-8. doi: 10.1016/j.annonc.2020. 06.015

[58] Di Lorenzo G, Buonerba L, Ingenito C, Crocetto F, Buonerba C, Libroia A, Sciarra A, Ragone G, Sanseverino R, Iaccarino S, Napodano G, Imbimbo C, Leo E, Kozlakidis Z, De Placido S. Clinical Characteristics of Metastatic Prostate Cancer Patients Infected with COVID19 in South Italy. Oncology. 2020;98(10):743-7. doi: $10.1159 / 000509434$

[59] Caffo O, Zagonel V, Baldessari C, Berruti A, Bortolus R, Buti S, Ceresoli GL, Donini M, Ermacora P, Fornarini G, Fratino L, Masini C, Massari F, Mosca A, Mucciarini C, Procopio G, Tucci M, Verri E, Zucali P, Buttigliero C. On the relationship between androgen-deprivation therapy for prostate cancer and risk of infection by SARS-CoV-2. Ann Oncol. 2020;31(10):1415-6. doi: 10.1016/j.annonc.2020.06.005

[60] Sanchez LR, Cathelineau X, Pinto AMA, BorqueFernando Á, Gil MJ, Yee CH, Sanchez-Salas R. Clinical and Surgical Assistance in Prostate Cancer during the COVID-19 Pandemic: Implementation of assistance protocols. Int Braz J Urol. 2020;46(suppl.1):50-61. doi: 10.1590/S1677-5538.IBJU.2020.S106

[61] Flannigan R, Sundar M, Weller S, Ivanov N, Hu M, Dayan M, Chen C, Wu E, Goldenberg L, Higano CS. Pearls to Pivoting a Multidisciplinary Prostate Cancer Survivorship Program During the COVID-19 Pandemic. Eur Urol Oncol. 2020;3(4):397-9. doi: 10.1016/j.euo.2020. 05.008

[62] Ginsburg KB, Curtis GL, Timar RE, George AK, Cher ML. Delayed Radical Prostatectomy is Not Associated with Adverse Oncologic Outcomes: Implications for Men Experiencing Surgical Delay Due to the COVID19 Pandemic. J Urol. 2020;204(4):720-5. doi: 10.1097/ JU.0000000000001089

[63] Montopoli M, Zumerle S, Vettor R, Rugge M, Zorzi M, Catapano CV, Carbone GM, Cavalli A, Pagano F, Ragazzi E, Prayer-Galetti T, Alimonti A. Androgen-deprivation therapies for prostate cancer and risk of infection by SARS-CoV-2: a population-based study $(N=4532)$. Ann Oncol. 2020;31(8):1040-5. doi: 10.1016/j.annonc.2020. 04.479

[64] Sean Ong XR, Condon B, Bagguley D, Lawrentschuk N, Azad A, Murphy D. Safety first: evidence for delay of radical prostatectomy without use of androgen deprivation therapy during COVID-19. Future Oncol. 2020;16(20): 1409-11. doi: 10.2217/fon-2020-0388
[65] Assi T, Ibrahim N, K Abboud RM, Kattan C, Rassy E, Nemr E, Kattan J. The management of patients with metastatic prostate cancer during the COVID-19 pandemic. Future Oncol. 2020;16(20):1455-61. doi: 10.2217/ fon-2020-0361

[66] Bhowmick NA, Oft J, Dorff T, Pal S, Agarwal N, Figlin RA, Posadas EM, Freedland SJ, Gong J. COVID19 and androgen-targeted therapy for prostate cancer patients. Endocr Relat Cancer. 2020;27(9):R281-R292. doi: 10.1530/ERC-20-0165

[67] Leeman JE, Nguyen PL. Less Is More During COVID 19. Int J Radiat Oncol Biol Phys. 2020;108(2):339. doi: 10.1016/j.ijrobp.2020.07.010

[68] Cattrini C, Bersanelli M, Latocca MM, Conte B, Vallome G, Boccardo F. Sex Hormones and Hormone Therapy during COVID-19 Pandemic: Implications for Patients with Cancer. Cancers (Basel). 2020;12(8):2325. doi: 10.3390/cancers 12082325

[69] Bahmad HF, Abou-Kheir W. Crosstalk between COVID19 and prostate cancer. Prostate Cancer Prostatic Dis. 2020;23(4):561-3. doi: 10.1038/s41391-020-0262-y

[70] Zaorsky NG, Yu JB, McBride SM, Dess RT, Jackson WC, Mahal BA, Chen R, Choudhury A, Henry A, Syndikus I, Mitin T, Tree A, Kishan AU, Spratt DE. Prostate Cancer Radiation Therapy Recommendations in Response to COVID-19. Adv Radiat Oncol. 2020;5(4):659-65. doi: 10.1016/j.adro.2020.03.010

[71] Obek C, Doganca T, Argun OB, Kural AR. Management of prostate cancer patients during COVID-19 pandemic. Prostate Cancer Prostatic Dis. 2020;23(3):398-406. doi: 10.1038/s41391-020-0258-7

[72] Moschovas MC, Sighinolfi MC, Rocco B, Bhat S, Onol F, Rogers T, Patel V. Balancing the Effects of COVID19 Against Potential Progression and Mortality in Highrisk Prostate Cancer. Eur Urol. 2020;78(1):e14-e15. doi: 10.1016/j.eururo.2020.04.028

[73] Sciarra A, Salciccia S, Maggi M, Del Giudice F, Busetto GM, Musio D, Ciardi A, Catalano C, Cortesi E, Panebianco V. Elective procedures for prostate cancer in the time of Covid-19: a multidisciplinary team experience. Prostate Cancer Prostatic Dis. 2020:1-3. doi: 10.1038/ s41391-020-0240-4

[74] Kokorovic A, So AI, Hotte SJ, Black PC, Danielson B, Emmenegger U, Finelli A, Niazi T, Pouliot F, Shayegan B, Sridhar S, Vigneault E, Loblaw A, Rendon RA. A Canadian framework for managing prostate cancer during the COVID-19 pandemic: Recommendations from the Canadian Urologic Oncology Group and the Canadian Urological Association. Can Urol Assoc J. 2020;14(6): 163-8. doi: 10.5489/cuaj.6667

[75] Bhat KRS, Moschovas MC, Rogers T, Onol FF, Corder C, Roof S, Sighinolfi C, Rocco B, Patel VR. COVID-19 model-based practice changes in managing a large prostate cancer practice: following the trends during a month-long ordeal. J Robot Surg. 2020:1-8. doi: 10.1007/s11701-02001100-8

[76] Barra S, Guarnieri A, di Monale E Bastia MB, Marcenaro M, Tornari E, Belgioia L, Magrini SM, Ricardi U, Corvò R. Short fractionation radiotherapy for early prostate cancer in the time of COVID-19: long-term excellent outcomes from a multicenter Italian trial suggest a larger adoption in clinical practice. Radiol Med. 2020:1-5. doi: 10.1007/s11547-020-01216-9

[77] Mollica V, Rizzo A, Massari F. The pivotal role of TMPRSS2 in coronavirus disease 2019 and prostate 
cancer. Future Oncol. 2020;16(27):2029-33. doi: 10.2217/ fon-2020-0571

[78] Klein EA, Li J, Milinovich A, Schold JD, Sharifi N, Kat$\tan$ MW, Jehi L. Androgen Deprivation Therapy in Men with Prostate Cancer Does Not Affect Risk of Infection with SARS-CoV-2. J Urol. 2021;205(2):441-3. doi: 10.1097/JU.0000000000001338

[79] Caffo O, Gasparro D, Di Lorenzo G, Volta AD, Guglielmini P, Zucali P, Bortolus R, Cavo A, Ceresoli G, Chiari R, Fornarini G, Fratino L, Iaculli A, Maruzzo M, Masini C, Morelli F, Mucciarini C, Procopio G, Sabbatini R, Verri E, Kinspergher S, Maines F, Messina C, Veccia A, Donini M. Incidence and outcomes of severe acute respiratory syndrome coronavirus 2 infection in patients with metastatic castration-resistant prostate cancer. Eur J Cancer. 2020;140:140-6. doi:10.1016/j.ejca.2020. 09.018

[80] Annis T, Pleasants S, Hultman G, Lindemann E, Thompson JA, Billecke S, Badlani S, Melton GB. Rapid implementation of a COVID-19 remote patient monitoring program. J Am Med Inform Assoc. 2020;27(8):1326-30. doi: 10.1093/jamia/ocaa097

[81] Griffiths W, Frew JA, Chandler R, Jiang XY, Pedley ID, Pearson RA. Prostate Ultrahypofractionation - Rising to Challenges Presents Opportunities in the COVID-19 Era. Clin Oncol (R Coll Radiol). 2021;33(1):e90. doi:10.1016/ j.clon.2020.10.012

[82] Fantin JPP, Spessoto LCF, Facio Junior FN. In the time of corona - is it safe to delay treatment for prostate cancer? Rev Assoc Med Bras (1992). 2020;66(4):388-9. doi:10. 1590/1806-9282.66.4.388

[83] Ribal MJ, Cornford P, Briganti A, Knoll T, Gravas S, Babjuk M, Harding C, Breda A, Bex A; GORRG Group, Rassweiler JJ, Gözen AS, Pini G, Liatsikos E, Giannarini G, Mottrie A, Subramaniam R, Sofikitis N, Rocco BMC, Xie LP, Witjes JA, Mottet N, Ljungberg B, Rouprêt M, Laguna MP, Salonia A, Bonkat G, Blok BFM, Türk C, Radmayr C, Kitrey ND, Engeler DS, Lumen N, Hakenberg OW, Watkin N, Hamid R, Olsburgh J, Darraugh J, Shepherd R, Smith EJ, Chapple CR, Stenzl A, Van Poppel H, Wirth M, Sønksen J, N’Dow J; EAU Section Offices and the EAU Guidelines Panels. European Association of Urology Guidelines Office Rapid Reaction Group: An Organisation-wide Collaborative Effort to Adapt the European Association of Urology Guidelines Recommendations to the Coronavirus Disease 2019 Era. Eur Urol. 2020;78(1):21-8. doi: 10.1016/j.eururo.2020.04.056

[84] Savin Z, Dekalo S, Marom R, Barnes S, Gitstein G, Mabjeesh NJ, Matzkin H, Yossepowitch O, Keren-Paz G, Mano R. The effect of delaying transperineal fusion biopsy of the prostate for patients with suspicious MRI findings-Implications for the COVID-19 era. Urol Oncol. 2021;39(1):73.e1-73.e8. doi: 10.1016/j.urolonc.2020. 07.009

[85] Cahill D. How the Martini-Klinik handled prostate surgery during COVID-19. BJU Int. 2020;126(3):E1. doi: 10.1111/bju. 15208

[86] Würnschimmel C, Maurer T, Knipper S, von Breunig F, Zoellner C, Thederan I, Huland H, Graefen M, Michl U. Martini-Klinik experience of prostate cancer surgery during the early phase of the COVID-19 pandemic. BJU Int. 2020;126(2):252-5. doi: 10.1111/bju.15115

[87] Stroman L, Cathcart P, Lamb A, Challacombe B, Popert R. A cross-section of UK prostate cancer diagnostics during the coronavirus disease 2019 (COVID-19) era - a shifting paradigm? BJU Int. 2021;127(1):30-34. doi: 10.1111/bju.15259

[88] Diamand R, Ploussard G, Roumiguié M, Oderda M, Benamran D, Fiard G, Peltier A, Simone G, Van Damme J, Malavaud B, Iselin C, Descotes JL, Roche JB, Quackels $\mathrm{T}$, Roumeguère $\mathrm{T}$, Albisinni $\mathrm{S}$. Timing and delay of radical prostatectomy do not lead to adverse oncologic outcomes: results from a large European cohort at the times of COVID-19 pandemic. World J Urol. 2020:1-8. doi: 10.1007/s00345-020-03402-w

[89] Popert R, Kum F, MacAskill F, Stroman L, Zisengwe G, Rusere J, Haire K, Challacombe B, Cathcart P. Our first month of delivering the prostate cancer diagnostic pathway within the limitations of COVID-19 using local anaesthesia transperineal biopsy. BJU Int. 2020;126(3):329-32. doi:10.1111/bju. 15120

[90] Tandogdu Z, Collins J, Shaw G, Rohn J, Koves B, Sachdeva A, Ghazi A, Haese A, Mottrie A, Kumar A, Sivaraman A, Tewari A, Challacombe B, Rocco B, Giedelman C, Wagner C, Rogers CG, Murphy DG, Pushkar D, Ogaya-Pinies G, Porter J, Ramesh Seetharam K, Graefen M, Orvieto MA, Covas Moschovas M, Schatloff $\mathrm{O}$, Wiklund $\mathrm{P}$, Coelho R, Valero R, de Reijke TM, Ahlering T, Rogers T, van der Poel HG, Patel V, Artibani W, Wagenlehner F, Nathan S, Erik Bjerklund Johansens T, Hawkey P, Kelly J. Management of patients who opt for radical prostatectomy during the COVID-19 pandemic: An International Accelerated Consensus Statement. BJU Int. 2020. doi: 10.1111/bju. 15299

[91] Tsimafeyeu I, Alekseeva G, Berkut M, Nosov A, Myslevtsev I, Andrianov A, Semenov A, Borisov P, Zukov R, Goutnik V, Savchuk S, Volkova M, Mukhina M. COVID19 in Patients With Renal Cell Carcinoma in the Russian Federation. Clin Genitourin Cancer. 2020:S1558-7673 (20)30167-1.

[92] Aeppli S, Eboulet EI, Eisen T, Escudier B, Fischer S, Larkin J, Gruenwald V, McDermott D, Oldenburg J, Omlin A, Porta C, Rini B, Schmidinger M, Sternberg C, Rothermundt C. Impact of COVID-19 pandemic on treatment patterns in metastatic clear cell renal cell carcinoma. ESMO Open. 2020;5(Suppl 3):e000852.

[93] Staehler M, Battle D, Pal SK, Bergerot CD. Counterbalancing COVID-19 with Cancer Surveillance and Therapy: A Survey of Patients with Renal Cell Carcinoma. Eur Urol Focus. 2020;S2405-4569(20)30259-5.

[94] Staehler MD, Battle DJ, Bergerot CD, Pal SK, Penson DF. COVID-19 and financial toxicity in patients with renal cell carcinoma. World J Urol. 2020;1-7.

[95] Ivanyi P, Grüllich C, Kroeger N, Gauler T, Johannsen M, Bedke J, Grünwald V; Interdisciplinary working group on renal tumors (IAG-N) of the German Cancer Society (DKG). Systemic treatment of advanced/metastatic renal cell carcinoma in the context of SARS-CoV-2 pandemic: recommendations from the interdisciplinary working group for renal tumors (IAG-N). J Cancer Res Clin Oncol. 2020;146(11):3075-8.

[96] Zequi SC, Abreu D. Consideration in the management of renal cell carcinoma during the COVID-19 pandemic. Int Braz J Urol. 2020;46(suppl.1):69-78.

[97] Mihalopoulos M, Dogra N, Mohamed N, Badani K, Kyprianou N. COVID-19 and Kidney Disease: Molecular Determinants and Clinical Implications in Renal Cancer. Eur Urol Focus. 2020;6(5):1086-96. 
[98] Ged Y, Markowski MC, Pierorazio PM. Advanced renal cell carcinoma and COVID-19 - a personal perspective. Nat Rev Urol. 2020;17(8):425-7.

[99] Bersanelli M. Controversies about COVID-19 and anticancer treatment with immune checkpoint inhibitors. Immunotherapy. 2020;12(5):269-73.

[100] Bersanelli M, Giannarelli D, De Giorgi U, Pignata S, Di Maio M, Verzoni E, Clemente A, Guadalupi V, Signorelli D, Tiseo M, Giusti R, Filetti M, Di Napoli M, Calvetti L, Cappetta A, Ermacora P, Zara D, Barbieri F, Baldessari C, Scotti V, Mazzoni F, Veccia A, Guglielmini PF, Maruzzo M, Rossi E, Grossi F, Casadei C, Cortellini A, Verderame F, Montesarchio V, Rizzo M, Mencoboni M, Zustovich F, Fratino L, Cinieri S, Negrini G, Banzi M, Sorarù M, Zucali PA, Lacidogna G, Russo A, Battelli N, Fornarini G, Mucciarini C, Bracarda S, Bonetti A, Pezzuolo D, Longo L, Sartori D, Iannopollo M, Cavanna L, Meriggi F, Tassinari D, Corbo C, Gernone A, Prati V, Carnio S, Giordano P, Dicorato AM, Verusio C, Atzori F, Carrozza F, Gori S, Castro A, Pilotto S, Vaccaro V, Garzoli E, Di Costanzo F, Maiello E, Labianca R, Pinto C, Tognetto M, Buti S. Symptomatic COVID-19 in advanced-cancer patients treated with immune-checkpoint inhibitors: prospective analysis from a multicentre observational trial by FICOG. Ther Adv Med Oncol. 2020;12:1758835920968463.

[101] Szabados B, Abu-Ghanem Y, Grant M, Choy J, Bex A, Powles T. Clinical Characteristics and Outcome for Four SARS-CoV-2-infected Cancer Patients Treated with Immune Checkpoint Inhibitors. Eur Urol. 2020;78(2): 276-80.

[102] Zheng Z, Jemal A, Han X, Guy GP Jr, Li C, Davidoff AJ, Banegas MP, Ekwueme DU, Yabroff KR. Medical financial hardship among cancer survivors in the United States. Cancer. 2019;125(10):1737-47.

[103] Herts BR, Silverman SG, Hindman NM, Uzzo RG, Hartman RP, Israel GM, Baumgarten DA, Berland LL, Pandharipande PV. Management of the Incidental Renal Mass on CT: A White Paper of the ACR Incidental Findings Committee. J Am Coll Radiol. 2018;15(2):264-73.

[104] de Leo D, Trabucchi M. COVID-19 and the Fears of Italian Senior Citizens. Int J Environ Res Public Health. 2020;17(10):3572.

[105] Hamilton W. Cancer diagnostic delay in the COVID19 era: what happens next? Lancet Oncol. 2020;21(8): 1000-2.

[106] Bersanelli M, Buti S, Rizzo M. The need for new algorithms of treatment sequencing in clear-cell metastatic renal cell carcinoma. Expert Rev Anticancer Ther. 2020: $1-12$.

[107] Sud A, Torr B, Jones ME, Broggio J, Scott S, Loveday C, Garrett A, Gronthoud F, Nicol DL, Jhanji S, Boyce SA, Williams M, Riboli E, Muller DC, Kipps E, Larkin J, Navani N, Swanton C, Lyratzopoulos G, McFerran E, Lawler M, Houlston R, Turnbull C. Effect of delays in the 2-week-wait cancer referral pathway during the COVID19 pandemic on cancer survival in the UK: a modelling study. Lancet Oncol. 2020;21(8):1035-44.

[108] Srivastava A, Patel HV, Kim S, Shinder B, Sterling J, Tabakin AL, Polotti CF, Saraiya B, Mayer T, Kim IY, Ghodoussipour S, Patel HD, Jang TL, Singer EA. Delaying surgery for clinical T1b-T2bN0M0 renal cell carcinoma: Oncologic implications in the COVID-19 era and beyond. Urol Oncol. 2020:S1078-1439(20)30485-3

[109] Mir MC, Capitanio U, Bertolo R, Ouzaid I, Salagierski M, Kriegmair M, Volpe A, Jewett MAS, Kutikov
A, Pierorazio PM; Young Academic Urologists Kidney Cancer working group of the European Urological Association. Role of Active Surveillance for Localized Small Renal Masses. Eur Urol Oncol. 2018;1(3): 177-87.

[110] Liu Y, Cox SR, Morita T, Kourembanas S. Hypoxia regulates vascular endothelial growth factor gene expression in endothelial cells. Identification of a 5 ' enhancer. Circ Res. 1995;77(3):638-43.

[111] Lee CG, Link H, Baluk P, Homer RJ, Chapoval S, Bhandari V, Kang MJ, Cohn L, Kim YK, McDonald DM, Elias JA. Vascular endothelial growth factor (VEGF) induces remodeling and enhances $\mathrm{TH} 2$-mediated sensitization and inflammation in the lung. Nat Med. 2004;10(10): 1095-103.

[112] Kaner RJ, Ladetto JV, Singh R, Fukuda N, Matthay MA, Crystal RG. Lung overexpression of the vascular endothelial growth factor gene induces pulmonary edema. Am J Respir Cell Mol Biol. 2000;22(6):657-64.

[113] Liu Q, Wang RS, Qu GQ, Wang YY, Liu P, Zhu YZ, Fei G, Ren L, Zhou YW, Liu L. Gross examination report of a COVID-19 death autopsy. Fa Yi Xue Za Zhi. 2020;36(1):21-3.

[114] Tian S, Hu W, Niu L, Liu H, Xu H, Xiao SY. Pulmonary Pathology of Early-Phase 2019 Novel Coronavirus (COVID-19) Pneumonia in Two Patients With Lung Cancer. J Thorac Oncol. 2020;15(5):700-4.

[115] Pang J, Xu F, Aondio G, Li Y, Fumagalli A, Lu M, Valmadre G, Wei J, Bian Y, Canesi M, Damiani G, Zhang Y, Yu D, Chen J, Ji X, Sui W, Wang B, Wu S, Kovacs A, Revera M, Wang H, Jing X, Zhang Y, Chen Y, Cao Y. Efficacy and tolerability of bevacizumab in patients with severe Covid-19. Nat Commun. 2021;12(1):814.

[116] Rossi E, Schinzari G, Tortora G. Pneumonitis from immune checkpoint inhibitors and COVID-19: current concern in cancer treatment. J Immunother Cancer. 2020; 8(2):e000952.

[117] Russano M, Citarella F, Napolitano A, Dell'Aquila E, Cortellini A, Pantano F, Vincenzi B, Tonini G, Santini D. COVID-19 pneumonia and immune-related pneumonitis: critical issues on differential diagnosis, potential interactions, and management. Expert Opin Biol Ther. 2020;20(9):959-64.

[118] Bersanelli M, Giannarelli D, Leonetti A, Buti S, Tiseo M, Nouvenne A, Ticinesi A, Meschi T, Procopio G, Danielli $\mathrm{R}$. The right immune-modulation at the right time: Thy$\operatorname{mosin} \alpha 1$ for prevention of severe Covid-19 in cancer patients. Future Oncology. 2020.

[119] Vivarelli S, Falzone L, Grillo CM, Scandurra G, Torino F, Libra M. Cancer Management during COVID19 Pandemic: Is Immune Checkpoint Inhibitors-Based Immunotherapy Harmful or Beneficial? Cancers (Basel). 2020;12(8):2237.

[120] Di Cosimo S, Malfettone A, Pérez-García JM, LlombartCussac A, Miceli R, Curigliano G, Cortés J. Immune checkpoint inhibitors: a physiology-driven approach to the treatment of coronavirus disease 2019. Eur J Cancer. 2020; 135:62-5.

[121] Powles T, Albiges L, Staehler M, Bensalah K, Dabestani S, Giles RH, Hofmann F, Hora M, Kuczyk MA, Lam TB, Marconi L, Merseburger AS, Fernández-Pello S, Tahbaz R, Volpe A, Ljungberg B, Bex A. Updated European Association of Urology Guidelines: Recommendations for the Treatment of First-line Metastatic Clear Cell Renal Cancer. Eur Urol. 2018;73(3):311-5. 
[122] Kim K, Ko Y, Ko DS, Kim YH. Prognostic Significance of COVID-19 Receptor ACE2 and Recommendation for Antihypertensive Drug in Renal Cell Carcinoma. Biomed Res Int. 2020;2020:2054376

[123] Furuhashi M, Moniwa N, Mita T, Fuseya T, Ishimura S, Ohno K, Shibata S, Tanaka M, Watanabe Y, Akasaka H, Ohnishi H, Yoshida H, Takizawa H, Saitoh S, Ura N, Shimamoto K, Miura T. Urinary angiotensin-converting enzyme 2 in hypertensive patients may be increased by olmesartan, an angiotensin II receptor blocker. Am J Hypert. 2015;28(1):15-21.

[124] Tripathi SC, Deshmukh V, Creighton CJ, Patil A. Renal Carcinoma Is Associated With Increased Risk of Coronavirus Infections. Front Mol Biosci. 2020;7:579422.
[125] Zhang Z, Li L, Li M, Wang X. The SARS-CoV-2 host cell receptor ACE2 correlates positively with immunotherapy response and is a potential protective factor for cancer progression. Comput Struct Biotechnol J. 2020;18:2438-44.

[126] Porta C. Editorial debate: Challenges we oncologists, working within a universal healthcare system, have to face in these hard times. ESMO Open. 2020;5:e000790.

[127] Cervantes A. Editorial debate: Challenges we oncologists, working within a universal healthcare system, have to face in these hard times. ESMO Open. 2020;5:e000800. 